\title{
Structure-based discovery of novel US28 small molecule ligands with different modes of action
}

Lückmann, Michael; Amarandi, Roxana-Maria; Papargyri, Natalia; Høy Jakobsen, Mette; Christiansen, Elisabeth; Jensen, Lars Juhl; Pui, Aurel; Schwartz, Thue W.; Rosenkilde, Mette M.; Frimurer, Thomas M.

Published in:

Chemical Biology and Drug Design

Link to article, DOI:

$10.1111 /$ cbdd. 12848

Publication date:

2017

Document Version

Peer reviewed version

Link back to DTU Orbit

Citation (APA):

Lückmann, M., Amarandi, R-M., Papargyri, N., Høy Jakobsen, M., Christiansen, E., Jensen, L. J., Pui, A., Schwartz, T. W., Rosenkilde, M. M., \& Frimurer, T. M. (2017). Structure-based discovery of novel US28 small molecule ligands with different modes of action. Chemical Biology and Drug Design, 89(3), 289-296. https://doi.org/10.1111/cbdd.12848

\section{General rights}

Copyright and moral rights for the publications made accessible in the public portal are retained by the authors and/or other copyright owners and it is a condition of accessing publications that users recognise and abide by the legal requirements associated with these rights.

- Users may download and print one copy of any publication from the public portal for the purpose of private study or research.

- You may not further distribute the material or use it for any profit-making activity or commercial gain

- You may freely distribute the URL identifying the publication in the public portal 


\title{
Structure-based Discovery of Novel US28 Small
}

\section{Molecule Ligands with Different Modes of Action}

\author{
Short Title: Discovery of Novel US28 Small Molecule Ligands
}

Michael Lückmann ${ }^{1,2+}$, Roxana-Maria Amarandi ${ }^{1,3+}$, Natalia Papargyri ${ }^{1,4}$, Mette H. Jakobsen ${ }^{l}$, Elisabeth Christiansen ${ }^{5}$, Lars J. Jensen ${ }^{6}$, Aurel Pui ${ }^{3}$, Thue W. Schwartz ${ }^{1,2}$, Mette M. Rosenkilde ${ }^{l}$ and Thomas M. Frimurer ${ }^{2,6^{*}}$

1. Department of Neuroscience and Pharmacology, University of Copenhagen, Blegdamsvej 3B, DK-2200 Copenhagen, Denmark. 2. Novo Nordisk Foundation Center for Basic Metabolic Research, University of Copenhagen, Blegdamsvej 3B, DK-2200 Copenhagen, Denmark. 3. Faculty of Chemistry, Alexandru Ioan Cuza University of Iaşi, Bd. Carol 1 No. 11, RO-700506 Iaşi, Romania. 4. Department of Systems Biology, Technical University of Denmark, Kemitorvet building 208, DK-2800, Kgs. Lyngby, Denmark. 5. Department of Physics, Chemistry and Pharmacy, University of Southern Denmark, Campusvej 55, DK-5230 Odense M, Denmark. 6. Novo Nordisk Foundation Center for Protein Research, University of Copenhagen, Blegdamsvej 3B, DK-2200 Copenhagen, Denmark.

$\$$ These authors contributed equally.

* Corresponding Author: Novo Nordisk Foundation Center for Basic Metabolic Research, Blegdamsvej 3B, DK-2200, Copenhagen, Denmark, Tel.: +45 302920 89, Fax: +45 3533 7101, Email: thomas.frimurer@,cpr.ku.dk 
Keywords:

Drug Discovery, G-Protein Coupled Receptor, Virtual Screening, Molecular Modeling

ABSTRACT

The human cytomegalovirus-encoded G protein-coupled receptor US28 is a constitutively active receptor, which can recognize various chemokines. Despite the recent determination of its $2.9 \AA$ crystal structure, potent and US28-specific tool compounds are still scarce. Here, we used structural information from a refined US28:VUF2274 complex for virtual screening of $>12$ million commercially available small molecule compounds. Using a combined receptor- and ligand-based approach, we tested 98 of the top $0.1 \%$ ranked compounds, revealing novel chemotypes as compared to the $\sim 1.45$ million known ligands in the ChEMBL database. Two compounds were confirmed as agonist and inverse agonist, respectively, in both IP accumulation and $\mathrm{Ca}^{2+}$ mobilization assays. The screening setup presented in this work is computationally inexpensive and therefore particularly useful in an academic setting as it enables simultaneous testing in binding as well as in different functional assays and/or species without actual chemical synthesis. 


\section{INTRODUCTION}

G protein-coupled receptors (GPCRs) regulate a vast range of physiological processes and continue to be at the center of attention of the pharmaceutical industry (1). In the past decade, multiple X-ray crystal structures of distinct GPCRs have been solved in complex with small molecule agonists, antagonists, allosteric modulators and a G protein $(2,3)$, including two human chemokine receptors in complex with small molecule, peptide and chemokine ligands (4-6). Chemokines (chemotactic cytokines) are protein ligands that are involved in immune response, wound healing and hostpathogen interactions (7). As an example of the latter, human cytomegalovirus (HCMV) encodes US28, a viral class A GPCR sharing 38\% sequence identity with human fractalkine receptor $\mathrm{CX}_{3} \mathrm{CR} 1$, suggesting that this virus hijacks chemokine signaling pathways as a mechanism to interfere with the host immune system (8). US28 is considered to be involved in viral dissemination, tumorigenesis and cardiovascular disease, such as transplant vascular sclerosis (9-11). Being a highly promiscuous receptor, US28 binds a number of different CC-chemokines (e.g. CCL5 (RANTES)), as well as $\mathrm{CX}_{3} \mathrm{CL} 1$ (fractalkine) that activate ligand and cell-type-specific signaling pathways $(9,12,13)$. This behavior has important consequences for rational drug design to target specific US28 functions in the context of HCMV pathogenesis. At present, the most important role of US28 in this context seems to be chemokine scavenging, a principle that was recently utilized for the development of the first immunotoxin which specifically kills HCMV-infected cells via targeting of US28 (14).

As the first small molecule compound reported to display activity on US28, Casarosa et al. identified VUF2274 as an inhibitor of constitutive activation of PLC signaling pathways in US28 (15). This compound had previously been discovered as an antagonist of the closely related CCR1 receptor (16). Although VUF2274 was described as an inverse agonist for US28, the high constitutive signaling and internalization of US28 might camouflage its actual agonist properties (17). Other small molecule compounds known to modulate US28 function or chemokine binding include piperidinecontaining VUF2274 analogues (18), Methiothepin, as well as structurally related dibenzodiazepines 
and dibenzazepines containing piperazine moieties (19, 20), flavonoids, chalcones (21) and tetrahydroisoquinoline derivatives (22), as well as a set of biphenyl amides with inverse agonist properties but low potency $(23,24)$. Thus, the current set of small molecule compounds cannot fully elucidate the relevance of US28 constitutive activity in viral pathogenesis.

As a complement to high-throughput screens (HTS) and medicinal chemistry optimization of known compounds (e.g. VUF2274), we used a combination of ligand and structure-based virtual screening to design a US28-focused mini library (98 compounds) that we then experimentally tested to identify novel small molecule ligands with different modes of action (agonist and inverse agonist).

\section{RESULTS}

\section{Modeling US28 and virtual screening}

Due to its similarity to the CCR5 inhibitor Maraviroc (PDB 4MBS) and its favorable drug-like size, we chose VUF2274 as a seed structure for the virtual ligand screening. Both CCR5 and US28 share a conserved glutamic acid at position $7.39^{\mathrm{VII}: 06}$ that serves as an anchor point for the positively charged tropane nitrogen bridge in Maraviroc in the case of CCR5 and for multiple other small molecules targeting CC-chemokine receptors (44). Residues are numbered using the Ballesteros (25) and Schwartz (26) numbering system. Regarding the fact that VUF2274 likewise has a positively charged moiety centrally placed in the molecule, we assumed a similar arrangement in US28 in which the piperidine nitrogen of VUF2274 forms a salt bridge with the carboxylic acid side chain of E7.39VII:06. This has also been proposed in previous VUF2274/US28 docking studies (15). The developed US28 receptor model in complex with VUF2274 shows high structural similarity to the recently published US28 X-ray crystal structure, which was published after the majority of our experiments had been completed (27). 
Our virtual screening workflow (Figure 1) included both receptor-based steps (Figure 1A-C) and a ligand-based approach (Figure 1D-F). In the former, we generated a homology model of US28 based on the closely related CCR5 receptor in complex with the small molecule HIV entry inhibitor Maraviroc (PDB 4MBS) (Figure 1A). The model was subsequently energy minimized and used to create a refined US28:VUF2274 complex, guided by the position of Maraviroc in CCR5 (Figure 1B). After several cycles of side-chain and receptor-ligand minimization, the optimized binding conformation was used in the screening protocol (Figure 1C).

In the ligand-based approach (Figure 1D-F), the combined repertoire of $>12$ million biologically relevant screening molecules that were extracted from the ZINC database and stripped for counterions, assigned tautomers, protonation states and pre-computed 3D conformations (Figure 1D) (28). Initially, the binding conformation of VUF2274 was used as a seed structure for ligand-based similarity searches using Pharmacophore Multiplets that have been demonstrated to be effective for lead and scaffold-hopping $(29,30)$.

PharmacophoreMultiplets, generated form steric features, hydrophobic centroids, aromatic rings, hydrogen acceptors, hydrogen donors, cations and anions features, were decomposed into all possible pharmacophore feature triangulations (so-called Triplets) and converted into binary fingerprints, to search the pre-computed chemical vendor libraries (Figure 1E).

The resulting top 5\% (639,130 compounds) ranked molecules, were used for Atomic Property Field (APF) superposition, and globally optimized in the Atomic Property Field (APF) grid potential of VUF2274 in US28, using ICM v.3.8 (Molsoft L.L.C., San Diego, CA, USA) (Figure 1F). The APF concept relies on a continuous property distribution where chemical moieties are represented as vectors of atomic properties (31). For molecular template superposition, molecules were placed in the APF grid potential of VUF2274 in US28 and globally optimized based on APF and internal force field energy. This resulted in 25,797 compounds from prioritized vendors with an APF score below 170. 
In a recent benchmark study of docking with high throughput screening, approximately $50 \%$ of the false positive compounds had high internal energies (32). Thus, compounds with internal energy strain $>10$ were rejected. To obey basic drug-like criteria, we removed compounds with long alkyl chains and many rotatable bonds $(>12)$, as well as compounds with $\mathrm{MW}>500$ and $\operatorname{clogP}>5$. Subsequent clustering revealed 1,454 cluster representatives using a $T_{c}$ threshold $=0.3$, and selected compounds per cluster defined by the square-root of the cluster size. Finally, a US28-focused mini library containing 98 compounds were selected based on manual inspection of complementary interactions with the US28 receptor pocket (Figure $1 \mathrm{G}$ ).

\section{IP accumulation and $\mathrm{Ca}^{2+}$ mobilization assays reveal novel US28 ligands}

We then performed an experimental screening of the US28-focused mini library both in functional and binding assays (Figure 2). All compounds were initially screened at a single concentration (10 $\mu \mathrm{M}$ ) in inositol phosphate (IP) accumulation assays and in competition binding assays using radiolabeled $\mathrm{CX}_{3} \mathrm{CL} 1$. We followed up on hits with dose-response analysis. The functional screen based on IP accumulation (Figure 2A) identified two compounds (ZINC36408696, ZINC25946902) with agonist and one (ZINC38535746) with inverse agonist properties and the ability to increase or, respectively, decrease US28 activity by about 50\%. During follow-up experiments, ZINC25946902 showed $\sim 30 \%$ unspecific activity in a screen on mock-transfected cells (Figure S2) and was therefore not selected for further experiments. Dose-response curves of ZINC36408696 (Figure 2B) and ZINC38535746 (Figure 2C) indicated moderate potency (lower $\mu \mathrm{M}$-range) and efficacy, with the inverse agonist ZINC38535746 showing a 2-fold improved potency $\left(\mathrm{EC}_{50}=1.76 \mu \mathrm{M}\right)$ compared to VUF2274 $\left(\mathrm{EC}_{50}=3.50 \mu \mathrm{M}\right)(15)$. Notably, the efficacy of ZINC38535746 is improved compared to $\mathrm{CX}_{3} \mathrm{CL1}$ (43\% and 27\% decrease in basal constitutive activity levels for the small molecule and chemokine ligands, respectively (Figure 2A and 2C)). 
In the binding screen, (Figure S3), one compound (ZINC32509119) was able to displace radiolabeled $\mathrm{CX}_{3} \mathrm{CL} 1$ by about $50 \%$. However, LC-MS analysis indicated instability of this compound probably due to fragmentation under the respective conditions. Neither VUF2274 nor the small molecule compounds identified in this study (ZINC36408696 and ZINC38535746) were not able to displace $\left[{ }^{125} \mathrm{I}\right]-\mathrm{CX}_{3} \mathrm{CL} 1$.

Both compounds are predicted to bind to US28 in a similar fashion in which E7.39 ${ }^{\mathrm{VII}: 06}$ forms a salt bridge with the positively charged nitrogen in the central part of ZINC36408696 and ZINC38535746 (Figure 2D and 2E). Small difference can be observed in e.g. the orientation of W2.60 $1 \mathrm{II} 20$ and the additional hydrogen bonding possibility between the carbonyl oxygen of ZINC38535746 and the hydroxyl moiety of Y3.33 ${ }^{\text {III:09 }}$. Future mutagenesis studies could confirm the implication of the aforementioned residues in stabilizing the ligands in the receptor-binding pocket.

To confirm functional activity further downstream the $\mathrm{G}$ protein signaling cascade, we performed assays to measure intracellular $\mathrm{Ca}^{2+}$ mobilization upon stimulation with a $10 \mu \mathrm{M}$ concentration of ZINC36408696 and ZINC38535746 (Figure 3). The agonistic activation by ZINC36408696 appears to be constant over the length of the experiment. For VUF2274 and ZINC38535746 we observed an initial increase in fluorescence followed by a decrease below zero.

Notably, ZINC36408696 and ZINC38535746 share a similar substructure and topology in which the right-hand side (Figure 2B and 2C) consists of a bicyclic system linked by a one-atom linker to a central piperazine and piperidine ring, respectively. Both compounds have rather bulky substituents on the right-hand side that make favorable aromatic interactions with $\mathrm{W} 2.60^{\mathrm{II}: 20}$ in the models located in a pocket that overlaps with the $\mathrm{CX}_{3} \mathrm{CL} 1$ binding site in the US28 crystal structure.

To explore potential cross-reactivity on other chemokine receptors, we performed similarity searches (using Open Babel FP2 fingerprints) of ZINC36408696 and ZINC38535746 against 1.45 million annotated chemicals (including all annotated chemokine ligands) in the ChEMBL_20 database representing all major target classes (Figure S5) (33,34). Only ZINC36408696 had three 
analogues with $T_{c}>0.8$, and none of these were associated with significant activities or otherwise related to any GPCR targets. Therefore, from current ligand knowledge, limited cross reactivity to other chemokine receptors could be expected.

\section{DISCUSSION}

In this work we present the discovery of a novel small molecule agonist and an inverse agonist. The structure-based discovery process to select and experimentally test a focused chemical mini library, cherry-picked from the collective repertoire of chemicals available from commercial chemical vendors is particular useful in an academic setting as a complement to the systematic but costly highthroughput screenings and "random" experimental testing of large compound collections. It enables simultaneous testing in binding as well as in different functional assays and/or species, e.g. both human and rodent receptors without actual chemical synthesis.

The discovery of a diverse set of novel active compounds on the US28 receptor was achieved by computational screening that made use of structural ligand and receptor information by incorporating the refined VUF2274 binding conformation into the screening workflow. Since our US28:VUF2274 model was based on homology modeling using CCR5:Maraviroc as a template, we compared the quality of our model upon release of the US28 X-ray crystal structure. Burg et al., describe several features in the active-like structure of US28 that differ from the inactive CCR5 structure (27). However, all of these active-state hallmarks are located in the intracellular part of the receptor. For the site that interacts with the N-terminal "hook" of CX 3 CL1 in US28 and Maraviroc in CCR5, we find the two structures to be highly similar. Consequently, our CCR5-based US28 model showed high structural resemblance to the US28 crystal structure regarding the position of binding site residues, as defined by 28 residues located within $5 \AA$ of the binding pose of VUF2274 $\left(\mathrm{C}_{\alpha}-\mathrm{RMSD}=0.84 \AA\right)$. For comparison: the $\mathrm{C}_{\alpha}$-RMSD of 24 residues in $5 \AA$ distance to Maraviroc in CCR5 (PDB 4MBS) 
to the US28 crystal structure is $3.09 \AA$ (PDB 4XT1). Furthermore, our assumption that VUF2274 shares a similar binding mode with Maraviroc in CCR5 was supported by the observation that both small molecules conceivably mimic the bonding chemistry of the N-terminal hook of $\mathrm{CX}_{3} \mathrm{CL} 1$ (27).

With respect to the potentially overlapping binding modes of $\mathrm{CX}_{3} \mathrm{CL} 1$ and VUF2274, it was surprising to identify a set of compounds with diverse pharmacological properties as ZINC36408696 and ZINC38535746. In our refined model of the US28:ZINC36408696 and the US28:ZINC38535746 complex we observe a partial overlap with the N-terminal hook of $\mathrm{CX}_{3} \mathrm{CL} 1$ in the US28-crystal structure (see Figure S4). 30 out of 59 atoms (ZINC36408696) and 29 out of 56 atoms (ZINC38535746), respectively, violate Van-der-Waals radii of $\mathrm{CX}_{3} \mathrm{CL} 1$, pointing to a significant sterical overlap of these ligands. The observed lack of $\mathrm{CX}_{3}$ CL1-displacement by ZINC36408696, ZINC38535746 and VUF2274 (Figure S3) is therefore unexpected. However, non-competitive behavior of ligands with similar binding modes has been observed previously (35) A possible explanation might be a multi-step binding model of $\mathrm{CX}_{3} \mathrm{CL} 1$ to US28. In this model, usually, the first interaction step is facilitated by tyrosine-sulfation of $\mathrm{D} / \mathrm{Y}$-rich motifs in the $\mathrm{N}$-terminus of the receptor that consequently contribute to charge-charge interactions with the positively charged residues of the chemokine (36). It is conceivable that the initial binding step taking place at the extracellular receptor surface can still occur in the presence of a more deeply buried small molecule ligand. Further, it has previously been shown that CC chemokines do not completely displace $\mathrm{CX}_{3} \mathrm{CL} 1$ from US28, while $\mathrm{CX}_{3} \mathrm{CL} 1$ can displace all $\mathrm{CC}$ chemokines with a greater affinity than the homologous unlabeled CCchemokines (13). While this could be caused by a partial overlap of chemokine binding sites, it could also indicate a differential conformational stabilization by CC chemokines, on one hand, and $\mathrm{CX}_{3} \mathrm{CL} 1$ on the other hand. At the same time, complete $\mathrm{CC}$ chemokine displacement by $\mathrm{CX}_{3} \mathrm{CL} 1$ could suggest a more stable conformation for US28 when this chemokine in bound, with reduced recognition of CC chemokines. Therefore, the lack of $\mathrm{CX}_{3}$ CL1-displacement for ZINC36408696, ZINC38535746 and VUF2274 might be due to the higher conformational stability of the $\mathrm{CX}_{3} \mathrm{CL1}$ :US28 receptor complex. 
Both ZINC36408696 and ZINC38535746 exhibit functional activity in IP accumulation as well as calcium signaling assays with micromolar potency but opposing signaling effects. Structural interpretation of these results is challenging due to the high level of ligand-independent internalization and constitutive activity of US28 that has been reported in discrepancies between signaling assays showing $\mathrm{CX}_{3} \mathrm{CL} 1$ and VUF2274 to exhibit both agonist and inverse agonist properties ("camouflaged agonism") (17,39). This behavior might also complicate the comparison between different assays, such as the "fast" calcium release assay, in which immediate response to the ligand is measured, and the "slow" IP accumulation assay, in which a certain time is given for the signaling molecules to accumulate. While ZINC36408696 consistently appears as an agonist in both assays, the picture for ZINC38535746 is less clear. This points to an important roles of the time scale, in which constitutive internalization is occurring, and the level of constitutive signaling, as determining factors for receptor activity to be addressed by future studies.

\section{CONCLUSION}

The discovered ligands reported here represent valuable starting points for structure-based discovery to select and experimentally test iterative series of focused chemical mini libraries. In this process, positive as well as negative results could be used to refine/improve receptor/ligand-based search models for the optimization of potent and efficacious lead series and novel pharmacological tool compounds to characterize the role of US28 in the context of HCMV pathogenesis. Further, the computational tools and knowledge from this project can directly be translated to other receptors to accelerate the discovery of novel ligands e.g. for understudied chemokine receptors or receptors that have been particularly challenging to work with from a drug development point of view. 


\section{METHODS AND MATERIALS}

\section{Homology Modeling and Generation of the US28:VUF2274 Model}

The sequence of the US28 (strain Towne) was obtained from UniProt (P69333) and used for homology modeling using the ICM Interactive Modeling tool (Molsoft L.L.C., San Diego, CA, USA). The CCR5 X-ray crystal structure in complex with Maraviroc (PDB 4MBS) was used as a template (27\% sequence identity to US28, alignment shown in Figure S1). After a subsequent 300 steps of Cartesian minimization, a global side-chain minimization (300 moves) was performed to relax local strains in the protein structure. The minimized US28 model was superimposed to the crystal structure of CCR5 and used for ICM template docking of VUF2274 onto the position of Maraviroc in CCR5. The ICM Ligand Editor was used for several cycles of side-chain refinement and ligand minimization and the best-scored binding pose was selected as a seed structure for the virtual screening. Binding modes of hit compounds (ZINC36408696, ZINC38535746) were refined in the same manner.

\section{Virtual Screening}

The In Stock subset of the ZINC database (http://zinc.docking.org) containing 12,782,590

biologically relevant screening molecules that are stripped for counterions and assigned tautomers, protonation states and charges were stored in UNITY databases and assigned Triplet pharmacophore descriptors $(28,37)$. Initially, the binding conformation of VUF2274 was used in a

Triplet similarity search of the In Stock subset of the ZINC database. Secondly, the top 5\% (639,130 compounds) ranked molecules, were used for Atomic Property Field (APF) superposition, and globally optimized in the APF grid potential of the refined binding conformation of VUF2274 in US28 (31). Chemical filtering ( $\mathrm{MW}<500$, drug-likeness score $>0.2, \log \mathrm{P}<5$, nrotb $<12$, strain $<$ 10) and subsequent clustering of 25,797 compounds revealed 1,454 cluster representatives using a $\mathrm{T}_{\mathrm{c}}$ threshold $=0.3$ and selected compounds per cluster defined by the square-root of the cluster size. A total of 98 compounds (Table S1) were purchased for testing based on manual assessment to 
recapitulate chemical complementary and key interactions of the US28:VUF2274 model. Virtual screening was performed on a 40-core Intel ${ }^{\circledR}$ Xeon ${ }^{\circledR}$ CPU E5-2690 (3.0 GHz) Linux server.

\section{Compound Preparation}

All purchased compounds were centrifuged and subsequently dissolved in $100 \%$ dimethyl sulfoxide (DMSO) to achieve an initial concentration of $10 \mathrm{mM}$ and left to shake overnight. Dilution rows of the $10 \mathrm{mM}$ stock solutions were subsequently prepared to obtain concentrations suitable for cellbased assays.

\section{Cell culture and transfection}

COS-7 cells were grown in Dulbecco's modified Eagle's Medium 1885 supplemented with 10\% fetal bovine serum (v/v), 180 units $/ \mathrm{mL}$ penicillin, $45 \mu \mathrm{g} / \mathrm{mL}$ streptomycin and $2 \mathrm{mM}$ L-glutamine at $37^{\circ} \mathrm{C}$ in a $10 \% \mathrm{CO}_{2} / 90 \%$ humidified atmosphere. Transfection of cells was carried out using the calcium phosphate precipitation method, two days prior to functional and binding experiments $(40,41)$.

\section{Binding experiments}

COS-7 cells were transferred to poly-D-lysine-coated 24-well plates (Nunc) one day after transfection with US28 pcDNA3.1+ (up to 150,000 cells/well). The amount of cells seeded per well was chosen based on the receptor expression efficiency, aiming for a 5-10 \% specific binding of added radioactive ligand. Competition binding experiments were performed as described previously, in two steps: an initial single point evaluation of all compounds in fixed concentration $(10 \mu \mathrm{M})$, and a dose-response competition evaluation using increasing concentrations of compounds (ranging from $1 \mathrm{nM}$ to $10 \mu \mathrm{M})(14,42,43)$. The compounds for this second step were 
selected based on the level of radioactive chemokine displacement exhibited in the initial evaluation step. Briefly, two days after transfection, cells were incubated for $3 \mathrm{~h}$ at $4{ }^{\circ} \mathrm{C}$ with $10-15 \mathrm{pM}\left[{ }^{125} \mathrm{I}\right]-$ $\mathrm{CX}_{3} \mathrm{CL} 1$ and an appropriate amount of unlabeled ligand in $0.2 \mathrm{~mL}$ binding buffer ( $50 \mathrm{mM}$ HEPES buffer, $\mathrm{pH} 7.2$, containing $5 \mathrm{mM} \mathrm{MgCl}_{2}$ and $1 \mathrm{mM} \mathrm{CaCl}_{2}$, supplemented with $0.5 \%$ (w/v) BSA). Cells were subsequently washed twice with binding buffer containing $0.5 \mathrm{M} \mathrm{NaCl}$ before being lysed with $0.5 \mathrm{~mL} \mathrm{NaOH} 0.2 \mathrm{M}$ solution containing 1\% SDS (w/v). Radioactivity was measured using a WALLAC 1470 Wizard Gamma Counter (Perkin Elmer). Nonspecific binding was determined using $0.1 \mu \mathrm{M}$ unlabeled $\mathrm{CX}_{3} \mathrm{CL} 1$. All determinations were made in duplicate.

\section{Inositolphosphate accumulation assay}

COS-7 cells were transferred to poly-D-lysine-coated 96-well plates (Nunc) one day after transfection $\left(35,000\right.$ cells/well) and incubated for $24 \mathrm{~h}$ with $0.5 \mu \mathrm{Ci} / \mathrm{mL}\left[{ }^{3} \mathrm{H}\right]$-myo-inositol (Perkin

Elmer). Inositolphosphate levels were determined using a scintillation proximity assay as previously described, in two steps: an initial single point evaluation of all compounds in a fixed concentration $(10 \mu \mathrm{M})$, from which compounds identified as significant attenuators or amplifiers of US28-induced constitutive activity levels were selected to test in a dose-response functional evaluation step using increasing concentrations of compounds (ranging from $1 \mathrm{nM}$ to $10 \mu \mathrm{M})(45,46)$. Briefly, two days after transfection, cells were incubated for $90 \mathrm{~min}$ at $37^{\circ} \mathrm{C}$ with the appropriate amount of ligands in $0.1 \mathrm{~mL}$ HBSS (Gibco) containing $10 \mathrm{mM} \mathrm{LiCl}$ and then lysed by adding $40 \mu \mathrm{L}$ of ice-cold $10 \mathrm{mM}$ formic acid, followed by incubation for at least 45 minutes on ice. Subsequently, $35 \mu \mathrm{L}$ of the lysis solution were transferred to white 96 -well plates and mixed with $80 \mu \mathrm{L}$ poly-D-lysine-coated YSi bead solution (Perkin Elmer). The plates were sealed and shaken at full speed for at least $30 \mathrm{~min}$, followed by centrifugation for $5 \mathrm{~min}$ at $1500 \mathrm{rpm}$. The beads were allowed to settle for $8 \mathrm{~h}$ before quantifying the generated $\left[{ }^{3} \mathrm{H}\right]$ inositolphosphates with a Packard TopCount NXT ${ }^{\mathrm{TM}}$ scintillation and 
luminescence counter (Perkin Elmer). Basal constitutive activity levels were determined in the presence of a $1 \%$ DMSO solution. All determinations were made in duplicate.

\section{$\mathrm{Ca}^{2+}$ mobilization assay}

Stable inducible clones of US28-HEK293 cells were grown in a humidified incubator at $37 \square \mathrm{C}$, $10 \% \mathrm{CO}_{2}$ in DMEM with $10 \%$ fetal bovine serum, $1 \%$ Penstrep, $0.1 \%$ blasticidin, and $0.2 \%$ hygromycin. The cells were seeded at $2 \times 10^{4}$ cells/well in poly-D-lysine coated 96 -well black wall clear flat bottom plates (costar). US28 expression was induced one day after seeding by addition of $0.25 \square \mathrm{g} / \mathrm{mL}$ tetracycline. After 24 hours induction, cells were loaded for 1 hour at $37 \square \mathrm{C}, 5 \% \mathrm{CO}_{2}$ in the dark with $0.2 \%$ Flou-4 and $0.2 \%$ Pluronic acid F-127 in loading buffer $\left(\mathrm{HBSS}^{++}\right.$Hepes buffer supplemented with 19.6 mM Hepes, $\mathrm{pH}$ 7.4, $1.25 \mathrm{mM}$ probenicid, $1 \mathrm{mM} \mathrm{CaCl} 2$ and $1 \mathrm{mM} \mathrm{MgCl}$ ). After 1 hour incubation cells were washed twice in pre-warmed loading buffer and finally $100 \square \mathrm{L}$ of the pre-warmed loading buffer was added to each well. Intracellular $\mathrm{Ca}^{2+}$ mobilization upon stimulation with the individual small molecules at $10 \mu \mathrm{M}$ concentration was monitored at $37 \square \mathrm{C}$ as fluorescence at excitation and emission wavelengths of 485 and $520 \mathrm{~nm}$, respectively. The measurements were performed using a Novostar microplate reader.

\section{Data analysis}

All statistical analyses were performed in GraphPad Prism v6.07 for Windows (GraphPad Software, San Diego, CA, USA). Single point evaluations represent the mean of at least three independent experiments. Results were normalized between (i) maximum $\left[{ }^{125} \mathrm{I}\right]-\mathrm{CX}_{3} \mathrm{CL} 1$ binding to US28expressing cells in the absence of cold $\mathrm{CX}_{3} \mathrm{CL} 1(100 \%)$ and unspecific $\left[{ }^{125} \mathrm{I}\right]-\mathrm{CX}_{3} \mathrm{CL} 1$ binding to US28-expressing cells in the presence of $0.1 \mu \mathrm{M}$ cold $\mathrm{CX}_{3} \mathrm{CL} 1(0 \%)$, in the case of binding experiments, and (ii) between the level of constitutive activity in US28-expressing cells (100\%) and background activity of mock-transfected cells $(0 \%$, in the case of functional IP accumulation experiments. Data from dose-response experiments were analyzed by nonlinear regression. $\mathrm{EC}_{50}$ and $\mathrm{IC}_{50}$ values represent the mean of at least three independent experiments performed in 
duplicate. Data from ligand induced calcium release experiments were normalized by scaling the fluorescence level to 0 at time 8.8 seconds, the time when the ligand or reference buffer was added to their respective measurement wells. The reference buffer response was subtracted from the ligand response in order to show the specific ligand induced changes in fluorescence.

\section{LC-MS analysis}

LC-MS analysis was performed using a Dionex UltiMate 3000 HPLC with a Gemini C18 column $(5 \mu \mathrm{m}, 4.6 \times 150 \mathrm{~mm})$; flow: $1 \mathrm{~mL} / \mathrm{min} ; 10 \% \mathrm{MeCN}$ in water $(0-1 \mathrm{~min}), 10-100 \% \mathrm{MeCN}$ in water (1$10 \mathrm{~min}), 100 \% \mathrm{MeCN}$ (11-15 min), with both solvents containing $0.1 \% \mathrm{HCOOH}$ as modifier, $\mathrm{UV}$ detection at $254 \mathrm{~nm}$; connected with Advion Expression CMS (ESI). High-resolution mass spectra (HRMS) were obtained on a Bruker micrOTOF-Q II (ESI). Purity and identity was determined by HPLC and confirmed by inspection of ${ }^{1} \mathrm{H}$ NMR spectra (see Figure S6, S7)

\section{FIGURE LEGENDS}

Figure 1: Virtual screening workflow. (A) Sequence alignment of US28 to CCR5 (for details see Figure S1) and the initial US28 homology model. (B) The US28 model was superimposed to the Xray crystal structure of CCR5 in complex with the small molecule inhibitor Maraviroc (PDB 4MBS) to generate a template for (C) ICM docking of the small molecule VUF2274 into the US28 binding cavity. (D) The binding pose of VUF2274 was used as a seed structure to search the combined 
catalogues of commercially available screening compounds. (E) First, compounds were screened based on pharmacophore multiplets similarity search. (F) The top 5\% of compounds were then selected by Tanimoto similarity and scored based on the Atomic Property Field (APF) method. (G) The final ranking, clustering, filtering and manual selection yielded a US28-focused mini library of 98 compounds that were experimentally tested.

Figure 2: Results of experimental screening based on IP-accumulation. (A) Scatterplot of the single concentration $(10 \mu \mathrm{M})$ screen of the US28-focused mini library containing 98 compounds. The agonist (ZINC36408696) and the inverse agonist (ZINC38535746) are indicated with colored dots (green, red, respectively). The nonspecific compound (ZINC25946902) is indicated as a grey dot. The maximum inhibition by $\mathrm{CX}_{3} \mathrm{CL} 1$ at a concentration of $100 \mathrm{nM}$ is indicated as a dotted line. (B, C) 2D chemical structure and dose-response curves for ZINC36408696, ZINC38535746 and VUF2274 (dotted line) (D, E) Refined conformation of the two compounds in the US28 model. Polar receptor-ligand interactions are indicated with light blue spheres in the binding conformation. Selected residues in direct ligand contact are labeled according to the Ballesteros and Schwartz (in superscript) numbering system $(25,26)$.

Figure 3 Ligand induced calcium release measured as fluorescence $(485-520 \mathrm{~nm})$ at a fixed concentration of $10 \mu \mathrm{M}$. Fluorescence curves of the agonist (ZINC36408696) and the inverse agonist (ZINC38535746) are indicated in green and red, respectively. SEM is shown in the corresponding light colors. Ligand or reference buffer was added to their respective measurement wells after 8.8 seconds. Fluorescence level was scaled to 0 at time 8.8 seconds in the post processing of the data. The reference buffer response was subtracted from the ligand response in order to show the specific ligand induced changes in fluorescence. 


\section{ACKNOWLEDGEMENTS}

The Novo Nordisk Foundation Center for Basic Metabolic Research and the Novo Nordisk

Foundation Center for Protein Research (NNF14CC0001) are supported by an unconditional grant

from the Novo Nordisk Foundation to the University of Copenhagen. M.L. received a faculty

scholarship from the Faculty of Health and Medical Sciences, University of Copenhagen. E.C. is

supported by a fellowship from the Lundbeck Foundation.

\section{CONFLICT OF INTEREST}

None declared.

\section{REFERENCES}

1. Wise A., Gearing K., Rees S. (2002) Target validation of G-protein coupled receptors. Drug Discov Today; 7:235-246.

2. Katritch V., Cherezov V., Stevens R.C. (2013) Structure-function of the G protein-coupled receptor superfamily. Annu Rev Pharmacol Toxicol;53:531-556.

3. Rasmussen S.G.F., DeVree B.T., Zou Y., Kruse A.C., Chung K.Y., Kobilka T.S., Thian F.S., Chae P.S., Pardon E., Calinski D., Mathiesen J.M., Shah S.T., Lyons J.A., Caffrey M., Gellman S.H., Steyaert J. et al. (2011) Crystal structure of the $\beta 2$ adrenergic receptor-Gs protein complex. Nature;477:549-555.

4. Tan Q., Zhu Y., Li J., Chen Z., Han G.W., Kufareva I., Li T., Ma L., Fenalti G., Li J., Zhang W., Xie X., Yang H., Jiang H., Cherezov V. et al. (2013) Structure of the CCR5 chemokine receptor-HIV entry inhibitor maraviroc complex. Science;341:1387-1390.

5. Wu B., Chien E.Y.T., Mol C.D., Fenalti G., Liu W., Katritch V., Abagyan R., Brooun A., Wells P., Bi F.C., Hamel D.J., Kuhn P., Handel T.M., Cherezov V., Stevens R.C. (2010) Structures of the CXCR4 chemokine GPCR with small-molecule and cyclic peptide antagonists. Science;330:1066-1071.

6. Qin L., Kufareva I., Holden L.G., Wang C., Zheng Y., Zhao C., Fenalti G., Wu H., Han G.W., Cherezov V., Abagyan R., Stevens R.C., Handel T.M. (2015) Structural biology. Crystal structure of the chemokine receptor CXCR4 in complex with a viral chemokine. Science;347:1117-1122.

7. Rosenkilde M.M., Schwartz T.W. (2004) The chemokine system -- a major regulator of angiogenesis in health and disease. APMIS;112:481-495.

8. Chee M.S., Satchwell S.C., Preddie E., Weston K.M., Barrell B.G. (1990) Human cytomegalovirus encodes three G protein-coupled receptor homologues. Nature;344:774777.

9. Vomaske J., Nelson J.A., Streblow D.N. (2009) Human Cytomegalovirus US28: a 
functionally selective chemokine binding receptor. Infect Disord Drug Targets;9:548-556.

10. Maussang D., Verzijl D., van Walsum M., Leurs R., Holl J., Pleskoff O., Michel D., van Dongen G.A., Smit M.J. (2006) Human cytomegalovirus-encoded chemokine receptor US28 promotes tumorigenesis. Proc Natl Acad Sci U S A;103:13068-13073.

11. Streblow D.N., Orloff S.L., Nelson J.A. (2001) The HCMV chemokine receptor US28 is a potential target in vascular disease. Curr Drug Targets Infect Disord;1:151-158.

12. Billstrom M.A., Johnson G.L., Avdi N.J., Worthen G.S. (1998) Intracellular signaling by the chemokine receptor US28 during human cytomegalovirus infection. J Virol;72:5535-5544.

13. Kledal T.N., Rosenkilde M.M., Schwartz T.W. (1998) Selective recognition of the membrane-bound $\mathrm{CX} 3 \mathrm{C}$ chemokine, fractalkine, by the human cytomegalovirus-encoded broad-spectrum receptor US28. FEBS Lett;441:209-214.

14. Spiess K., Jeppesen M.G., Malmgaard-Clausen M., Krzywkowski K., Dulal K., Cheng T., Hjortø G.M., Larsen O., Burg J.S., Jarvis M.A., Garcia K.C., Zhu H., Kledal T.N.,

Rosenkilde M.M. (2015) Rationally designed chemokine-based toxin targeting the viral G protein-coupled receptor US28 potently inhibits cytomegalovirus infection in vivo. Proc Natl Acad Sci U S A;112:8427-8432.

15. Casarosa P., Menge W.M., Minisini R., Otto C., van Heteren J., Jongejan A., Timmerman H., Moepps B., Kirchhoff F., Mertens T., Smit M.J., Leurs R. (2003) Identification of the first nonpeptidergic inverse agonist for a constitutively active viral-encoded $\mathrm{G}$ protein-coupled receptor. J Biol Chem;278:5172-5178.

16. Hesselgesser J. (1998) Identification and Characterization of Small Molecule Functional Antagonists of the CCR1 Chemokine Receptor. J Biol Chem;273:15687-15692.

17. Tschammer N. (2014) Allosteric modulation of the G protein-coupled US28 receptor of human cytomegalovirus: are the small-weight inverse agonist of US28 'camouflaged' agonists? Bioorg Med Chem Lett;24:3744-3747.

18. Hulshof JW, Vischer HF, Verheij MH, Fratantoni SA, Smit MJ, de Esch IJ, et al. (2006) Synthesis and pharmacological characterization of novel inverse agonists acting on the viralencoded chemokine receptor US28. Bioorg Med Chem;14:7213-30.

19. Schall TJ, Mcmaster BE, Dairaghi DJ. (March 7, 2002) Modulators of us28 (chemokines) for treating cytomegalovirus infections, US Patent WO2002017900 A2.

20. Vischer HF, Hulshof JW, Hulscher S, Fratantoni SA, Verheij MH, Victorina J, et al. (2010) Identification of novel allosteric nonpeptidergic inhibitors of the human cytomegalovirusencoded chemokine receptor US28. Bioorg Med Chem;18:675-88.

21. Kralj A, Nguyen MT, Tschammer N, Ocampo N, Gesiotto Q, Heinrich MR, et al. (2013) Development of flavonoid-based inverse agonists of the key signaling receptor US28 of human cytomegalovirus. J Med Chem;56:5019-32.

22. Kralj A, Wetzel A, Mahmoudian S, Stamminger T, Tschammer N, Heinrich MR (2011) Identification of novel allosteric modulators for the G-protein coupled US28 receptor of human cytomegalovirus. Bioorg Med Chem Lett;21:5446-50.

23. Dairaghi, D.J., Mcmaster, B.E., Schall, T.J. (March 7, 2002) Modulators of us28 (chemokines) for treating cytomegalovirus infections. US Patent WO 2002017900 A2.

24. Kralj A, Kurt E, Tschammer N, Heinrich MR (2014) Synthesis and biological evaluation of biphenyl amides that modulate the US28 receptor. ChemMedChem;9:151-68.

25. Ballesteros JA, Weinstein H (1995) Integrated methods for the construction of threedimensional models and computational probing of structure-function relations in G Proteincoupled receptors. Methods Neurosci;25:366-428.

26. Schwartz TW (1994) Locating ligand-binding sites in 7TM receptors by protein engineering. Curr Opin Biotechnol;5:434-44. 
27. Burg JS, Ingram JR, Venkatakrishnan AJ, Jude KM, Dukkipati A, Feinberg EN, et al. (2015) Structural biology. Structural basis for chemokine recognition and activation of a viral $\mathrm{G}$ protein-coupled receptor. Science;347:1113-7.

28. Irwin JJ, Sterling T, Mysinger MM, Bolstad ES, Coleman RG (2012) ZINC: a free tool to discover chemistry for biology. J Chem Inf Model;52:1757-68.

29. Fox PC, Wolohan PR, Abrahamian E, Clark RD (2008) Parameterization and conformational sampling effects in pharmacophore multiplet searching. J Chem Inf Model;48:2326-34.

30. Abrahamian E, Fox PC, Naerum L, Christensen IT, Thogersen H, Clark RD (2003) Efficient generation, storage, and manipulation of fully flexible pharmacophore multiplets and their use in 3-D similarity searching. J Chem Inf Comput Sci;43:458-68.

31. Totrov M (2008) Atomic property fields: generalized 3D pharmacophoric potential for automated ligand superposition, pharmacophore elucidation and 3D QSAR. Chem Biol Drug Des; 71:15-27.

32. Ferreira RS, Simeonov A, Jadhav A, Eidam O, Mott BT, Keiser MJ, et al. (2010) Complementarity between a docking and a high-throughput screen in discovering new cruzain inhibitors. J Med Chem;53:4891-905.

33 O’Boyle N.M., Banck M., James C.A., Morley C., Vandermeersch T., Hutchison G.R. (2011) Open Babel: An open chemical toolbox. J Cheminform;3:33.

34. Bento AP, Gaulton A, Hersey A, Bellis LJ, Chambers J, Davies M, et al. (2014) The ChEMBL bioactivity database: an update. Nucleic Acids Res;42:D1083-90.

35. Hauge M, Vestmar MA, Husted AS, Ekberg JP, Wright MJ, Di Salvo J et al. (2015) GPR40 (FFAR1) - Combined Gs and Gq signaling in vitro is associated with robust incretin secretagogue action ex vivo and in vivo. Mol Metab 2015;4:3-14.

36. Thiele S, Rosenkilde MM. Interaction of chemokines with their receptors--from initial chemokine binding to receptor activating steps. Curr Med Chem 2014;21:3594-3614.

37. SYBYL 8.0 TI, 1699 South Hanley Rd., St. Louis, Missouri, 63144, USA

38. Kuhn DE, Beall CJ, Kolattukudy PE (1995) The cytomegalovirus US28 protein binds multiple CC chemokines with high affinity. Biochem Biophys Res Commun;211:325-30.

39. Waldhoer M, Casarosa P, Rosenkilde MM, Smit MJ, Leurs R, Whistler JL, et al. (2003) The carboxyl terminus of human cytomegalovirus-encoded 7 transmembrane receptor US28 camouflages agonism by mediating constitutive endocytosis. J Biol Chem;278:19473-82.

40. Graham FL, van der Eb AJ (1973) A new technique for the assay of infectivity of human adenovirus 5 DNA. Virology;52:456-67.

41. Rosenkilde MM, Kledal TN, Brauner-Osborne H, Schwartz TW (1999) Agonists and inverse agonists for the herpesvirus 8-encoded constitutively active seven-transmembrane oncogene product, ORF-74. J Biol Chem;274:956-61.

42. Thiele S, Steen A, Jensen PC, Mokrosinski J, Frimurer TM, Rosenkilde MM (2011) Allosteric and orthosteric sites in CC chemokine receptor (CCR5), a chimeric receptor approach. J Biol Chem;286:37543-54.

43. Thiele S, Mungalpara J, Steen A, Rosenkilde MM, Vabeno J (2014) Determination of the binding mode for the cyclopentapeptide CXCR4 antagonist FC131 using a dual approach of ligand modifications and receptor mutagenesis. Br J Pharmacol;171:5313-29.

44. Rosenkilde MM, Schwartz TW. GluVII:06--a highly conserved and selective anchor point for non-peptide ligands in chemokine receptors. Curr Top Med Chem 2006;6:1319-1333.

45. Amarandi RM, Hjorto GM, Rosenkilde MM, Karlshoj S (2016) Probing Biased Signaling in Chemokine Receptors. Methods Enzymol;570:155-86

46. Jensen PC, Rosenkilde MM (2009) Chapter 8. Activation mechanisms of chemokine receptors. Methods Enzymol;461:171-90 


\section{ABBREVIATIONS}

APF, atomic property field; CCL5, chemokine (C-C motif) ligand 5 (RANTES); CCR5, CC chemokine receptor 5; $\mathrm{CX}_{3} \mathrm{C}$ chemokine receptor 1 (fractalkine receptor); $\mathrm{CX}_{3} \mathrm{CL} 1$, chemokine (C$\mathrm{X}_{3}-\mathrm{C}$ motif) ligand 1 (fractalkine); $\mathrm{CX}_{3} \mathrm{CR} 1$, DMEM, Dulbecco's Modified Eagle Medium; DMSO, dimethyl sulfoxide; GPCR, G protein coupled receptor; HBA, hydrogen bond donor; HBD, hydrogen bond acceptor; HBSS, Hank's balanced salt solution; HCMV, human cytomegalovirus; HTS, high-throughput screen; ICM, internal coordinate mechanics; IP, inositol phosphate; LC-MS, liquid chromatography-mass spectrometry; MW, molecular weight; nrotb, number of rotatable bonds; PLC, phospholipase C; RMSD, root-mean-square deviation; SAR, structure-activity relationship

\section{SUPPORTING INFORMATION}

The following files are available free of charge (Supporting_Information.pdf).

Figure S1: Sequence alignment of US28 (strain Towne) and human CCR5 (PDB 4MBS).

Table S1: US28-focused mini-library.

Figure S2: Effect on mock-transfected COS-7 cells (\%).

Figure S3: Results of experimental screening based on $\left[{ }^{125} \mathrm{I}\right]-\mathrm{CX}_{3} \mathrm{CL} 1$ displacement.

Figure S4: Binding mode comparison between ZINC36408696 \& ZINC38535746 and the crystallographic position of $\mathrm{CX}_{3} \mathrm{CL} 1$ in US28.

Figure S5: Similarity searches of ZINC36408696 and ZINC38535746 against 1.45 million annotated chemicals in the ChEMBL_20 database.

Figure S6: ${ }^{1} \mathrm{H}$ NMR spectrum of ZINC36408696.

Figure S7: ${ }^{1} \mathrm{H}$ NMR spectrum of ZINC38535746. 
